\title{
Effect of Controlled $\kappa$-Casein Hydrolysis on Rheological Properties of Acid Milk Gels
}

\author{
E. Gastaldi, ${ }^{*}$ N. Trial, ${ }^{*}$ C. Guillaume, ${ }^{\star}$ E. Bourret, $†$ N. Gontard, ${ }^{*}$ and J. L. Cuq ${ }^{\star}$ \\ *Laboratoire de Génie des Procédés et Sciences des Aliments, \\ Université Montpellier II, 34095 Montpellier Cedex 05, France \\ †Laboratorie de Physique Moléculaire et Structurale, \\ Faculté de Pharmacie de Montpellier, 34093 Montpellier Cedex 5, France.
}

\begin{abstract}
An experimental method based on the controlled chymosin-induced $\kappa$-casein hydrolysis of milk was proposed to modify micellar reactivity. Milk samples with a degree of $\kappa$-casein hydrolysis of 19,35 , and $51 \%$ were obtained. The physicochemical properties of partially converted casein micelles were determined. The net negative charge of casein micelles was reduced with increasing degree of $\kappa$-casein hydrolysis and a small but significant decrease in hydrodynamic diameter and micellar hydration were noted. Dynamic low amplitude oscillatory rheology was used to monitor the rheological properties of acid milk gels (GDL) made with partially chymosin-hydrolyzed milks in comparison with those of strictly acid and rennet gels. An increase in the gelation $\mathrm{pH}$ value was observed with increasing the degree of $\kappa$-casein hydrolysis. The moduli values ( $\mathrm{G}^{\prime}$ and $\left.\mathrm{G}^{\prime \prime}\right)$ reached $2 \mathrm{~h}$ after the point of gel were, for all degrees of hydrolysis tested, significantly higher than those of strictly rennet and acid gels. Comparison of changes in $\Delta \mathrm{G}^{\prime} / \Delta \mathrm{t}$ with time indicated differences in gel formation that could be related to the increased values of $\mathrm{G}^{\prime} \mathrm{ob}$ tained for acid gel made with chymosin-treated milk. At a given time after gelation $(2 \mathrm{~h}$ ), increasing the degree of $\kappa$-casein hydrolysis in milk led also to an increase in the loss tangent and the serum holding capacity of acid milk gels suggesting a correlation between these two parameters.
\end{abstract}

(Key words: $\kappa$-casein hydrolysis, acid milk gel, rheological property, serum-holding capacity)

Abbreviation key: CCP $=$ colloidal calcium phosphate, $\mathbf{C M P}=$ caseinomacropeptide, $\mathbf{D M S O}=$ dimethylsulfoxide, $\mathbf{E} / \mathbf{I}=$ enzyme/inhibitor, $\mathbf{E} / \mathbf{S}=$ enzyme/substrate, $\mathbf{G D L}=$ glucono- $\delta$-lactone, $\mathbf{t g}=$ gelation time .

Received February 16, 2002

Accepted June 19, 2002.

Corresponding author: E. Gastaldi; e-mail: gastaldi@arpb. univ-montp2.fr.

\section{INTRODUCTION}

Chemical and enzymatic modifications of protein is generally performed with the intention of changing not only the functionality of food proteins (Vojdani and Whitaker, 1994), but also of improving the fundamental knowledge of the mechanisms involved in food processing (Vidal et al., 1998). Among enzymatic modifications of casein, the hydrolysis of protein can be considered as a way to modify the number of polar groups, the hydrophilicity/hydrophobicity balance, and the molecular configuration leading generally to changes in its functionality and more particularly in its gelation properties. The conversion of milk to gel by the action of chymosin is the result of the hydrolysis of $\kappa$-casein (Phe 105-Met 106). This highly selective modification of protein structure initiates a sequence of events resulting in a gelation phenomenon traditionally used in cheese making.

Chymosin action involves an enzymatic reaction, in which chymosin splits the casein macropeptide, followed by the aggregation of the newly formed paracasein micelles if temperature and calcium activity are high enough (Tarodo and Alais, 1975). In agreement with the concept of steric repulsion (Horne, 1986), measurable aggregation only occurs after most macropeptide forming hairs have been removed, about 85 to $90 \%$ according to Dalgleish (1979). The stability of casein micelles against aggregation is primarily due to steric repulsion caused by hydrophilic hairs of $\kappa$-casein but also, at low temperature of $\beta$-casein (Roefs et al., 1990a). The probability that casein molecules in different micelles comes into contact of each other for a sufficient time to create new intermolecular bonds appears to depend on electrostatic as well as steric repulsion, which thereby affect aggregation rate (Bringe and Kinsella, 1987). Because of the polar and charged nature of the caseinomacropeptide part of the $\kappa$-casein, repulsion is considered as the dominant factor controlling the stability of the casein micelle system (Horne and Parker, 1981). 
The aim of this study was to modify the micellar surface reactivity by using chymosin to realize a partial controlled hydrolysis of $\kappa$-casein. To control this reaction, a specific acid protease inhibitor was added to milk when a desired degree of $\kappa$-casein hydrolysis was reached. Such a method can be directly applied on casein micelles in their natural environment, unlike most reports dealing with enzymatic modification of isolated milk constituents. The extent of enzymatic modification was related to the degree of $\kappa$-casein hydrolysis that could be controlled with a low temperature of incubation $\left(4^{\circ} \mathrm{C}\right)$. In such conditions, the two reactions implied in the chymosin hydrolysis, splitting of casein macropeptide and aggregation of paracasein micelles were uncoupled. Acid milk gels (GDL) were made from partially chymosin-hydrolyzed milk, and the rheological properties of gels obtained were compared to those of strictly acid or rennet milk gels. The effects of the degree of $\kappa$-casein hydrolysis on acid milk gels formation were thus investigated, and a discussion relied on rheological properties and serum holding capacity of resulting acid milk gels was finally proposed.

\section{MATERIALS AND METHODS}

\section{Skim Milk Reconstitution}

Reconstituted skim milk was made by dissolving a commercial low-heat powder (Lait Matines-SILI, Plouvien, France) at $12 \%(\mathrm{wt} / \mathrm{vol})$ in deionized water. The powder used in this study contained $3 \%(\mathrm{p} / \mathrm{p})$ moisture, $35.62 \%(\mathrm{p} / \mathrm{p})$ protein (total nitrogen $\times 6.38)$ and had a whey protein nitrogen index of $6 \mathrm{mg}$ of undenatured whey protein per gram of powder. Milk was stored at $4^{\circ} \mathrm{C}$ for $12 \mathrm{~h}$ after the addition of $250 \mathrm{mg} / \mathrm{L}$ of calcium as $\mathrm{CaCl}_{2}$ solution. To prevent bacterial growth, $0.04 \%$ (wt/vol) sodium azide was added.

\section{Preparation of Partially Chymosin Hydrolyzed Milk Samples}

Chymosin hydrolysis of $\kappa$-casein was realized at $4^{\circ} \mathrm{C}$ by using defined amount of a liquid chymosin preparation at $600 \mathrm{mg} / \mathrm{L}$ (Maxiren 120, DSM, France). Adequate amounts of a 10-fold water diluted chymosin solution $(10,20$, or $30 \mu \mathrm{l})$ were added to milk $(100 \mathrm{ml})$ to give an enzyme/substrate $(\mathbf{E} / \mathbf{S})$ molar ratio of 8,16 , and $36 \times 10^{-7}$, respectively (substrate was considered as $\kappa$-casein). In such conditions, a final enzyme concentration of, respectively 2 , 4 , and $6.10^{-10} M$ was obtained. After $15 \mathrm{~h}$ of incubation, the chymosin hydrolysis was stopped by the addition under vigorously stirring of an appropriate amount of Pepstatin A (Coger, Paris, France), an aspartic proteinase inhibitor, dissolved in dimethylsulfoxide (DMSO) to a concentration of $1 \mathrm{mM}$.
Pepstatin A was added to milk to give an enzyme/inhibitor $(\mathbf{E} / \mathbf{I})$ molar ratio of $2.10^{-5}$. Totally $\kappa$-casein hydrolyzed milk samples were obtained by adding $40 \mu \mathrm{l}$ of the chymosin preparation (Maxiren) to $100 \mathrm{ml}$ of skim milk and incubating $1 \mathrm{~h}$ at $30^{\circ} \mathrm{C}$.

\section{Determination of the Degree of $\kappa$-Casein Hydrolysis}

The quantitative determination of caseinomacropeptide (CMP) was performed by cation-exchange chromatographic analysis according to Leonil and Mollé (1991) by relating the areas to the amounts of CMP injected (Sigma-Aldrich, France). The degree of $\kappa$-casein hydrolysis was determined by comparing the CMP content of different milk samples to a totally hydrolyzed milk considered as 100\% $\kappa$-casein hydrolysis.

\section{Micellar Hydration, Hydrodynamic Diameter, and Zeta Potential Measurements}

The solvation water of casein micelles was determined by means of ultracentrifugation as previously described by Gastaldi et al. (1996) and was expressed as $\mathrm{g}$ of $\mathrm{H}_{2} \mathrm{O} / \mathrm{g}$ of dry pellet. Separation of the soluble and micellar phases was achieved by ultracentrifugation at $149,000 \times \mathrm{g}$ for $35 \mathrm{~min}$ at $30^{\circ} \mathrm{C}$ with a Beckman ultracentrifuge, rotor Ti 30 (Beckman Instruments France S.A., Gagny, France).

A Malvern Zeta Sizer 3000 (Malvern Instruments, Worcestershire, England) was used to evaluate by dynamic light scattering with a $5 \mathrm{~mW}$ He-Ne laser $(\lambda=$ $633 \mathrm{~nm}$ ) both the average hydrodynamic diameter and the electrokinetic potential of casein micelles with different levels of $\kappa$-casein hydrolysis. Casein micelles were examined in their natural ionic environment by suspending them in milk permeate obtained by milk filtration through Amicon YM10 membranes (Epernon, France). The milk dilutions used were 1:50 and 1:200 for average hydrodynamic diameter and average electrophoretic mobility measurements respectively. Temperature was controlled at $30 \pm 1^{\circ} \mathrm{C}$ by a Joule-Peltier device.

\section{Gel Formation}

Milks with different levels of $\kappa$-casein hydrolysis were acidified with $2 \%$ (wt/vol) Glucono- $\delta$-lactone (GDL) (Merck, Darmstadt, Germany) at $30^{\circ} \mathrm{C}$ and the acidification was followed as a function of time. The $\mathrm{pH}$ of the samples was regularly measured at $30 \pm 1^{\circ} \mathrm{C}$ using a Corning $125 \mathrm{pH}$ meter and was about 4.5 after $3 \mathrm{~h}$ of incubation. To allow comparison between the different types of gels, a rennet milk gel was also prepared at $30^{\circ} \mathrm{C}$ by adding to milk $0.025 \%$ ( $\mathrm{vol} / \mathrm{vol}$ ) of a commercial 
calf rennet Naturen (Chr. Hansen's Laboratory, Copenhagen, Denmark) which contains $61 \%$ chymosin and $39 \%$ bovine pepsin and corresponds to a total milk clotting activity of about 145 IMCU (international milkclotting units) $\mathrm{ml}^{-1}$.

\section{Dynamic Rheological Measurement}

Small deformation oscillatory measurements were performed on a Rheostress RS 100 (Haake, Karlsruhe, Germany) rheometer with a measuring system consisting in a cone-plate sensor system $(60 \mathrm{~mm}$ diameter, $2^{\circ}$ angle). Measurement of the storage modulus, $\left(\mathrm{G}^{\prime}\right)$, the loss modulus, $\left(\mathrm{G}^{\prime \prime}\right)$, and the loss tangent, $(\tan \delta)$, were performed continuously during milk gelation in oscillary mode. After the addition of GDL or rennet to milk, the mixture was stirred for 2 min and then an appropriate volume $(2 \mathrm{ml})$ of the mixture was transferred to the measuring system. A glass cloche was placed on the system to prevent evaporation. Samples were submitted to oscillation at a frequency of $0.1 \mathrm{~Hz}$ and the measurement interval was set at $120 \mathrm{~s}$ with a stress of $0.02 \mathrm{~Pa}$ which was found to be within the linear region for all milk gels tested in this study. Gelation time (tg) was defined as the time when $\mathrm{G}^{\prime}=\mathrm{G}^{\prime \prime}$ or tan $\delta=1$ (Tobitani et al., 1995).

\section{Evaluation of Serum-Holding Capacity of Gel}

A measure of serum-holding capacity was obtained by using a centrifugation test at $1000 \times g$ during 15 min according to Daviau et al. (2000). Aliquots of 15 $\mathrm{ml}$ of milk were placed into centrifugation tubes with appropriate coagulating agent (GDL or rennet) and held undisturbed in a water bath at $30^{\circ} \mathrm{C}$. The centrifugation test was realized $2 \mathrm{~h}$ after gel point was reached. The supernatant was poured off, weighed, and expressed as a percentage of gram of serum per $100 \mathrm{~g}$ of gel.

\section{Statistical Analysis}

Experimental data were represented as the mean values of duplicate or more analysis depending on the type of analysis and were subjected to ANOVA (StatView, Abacus Concepts, Inc., Berkeley, CA). Fisher's protected least significant difference (PLSD) test was used to compare pairwise means and differences between means were considered to be significant at $P$ $<0.05$.

\section{RESULTS AND DISCUSSION}

\section{Extent of $\kappa$-Casein Hydrolysis}

Partially $\kappa$-casein hydrolyzed micelles were obtained by treating milk with low concentrations of chymosin
Table 1. Extent of $\kappa$-casein hydrolysis in milk as related to the concentration of chymosin added and the concentration of Pepstatin A used to inhibit the reaction after $15 \mathrm{~h}$ incubation at $4^{\circ} \mathrm{C}$.

\begin{tabular}{lll}
$\begin{array}{l}\text { Chymosin } \\
\text { concentration }(M)\end{array}$ & $\begin{array}{l}\text { Pepstatin A } \\
\text { concentration }(M)\end{array}$ & $\begin{array}{l}\text { Degree of } \kappa \text {-casein } \\
\text { hydrolysis }(\%)^{1}\end{array}$ \\
\hline $2.10^{-10}$ & $1.10^{-5}$ & $19 \pm 0.8$ \\
$4.10^{-10}$ & $2.10^{-5}$ & $35 \pm 1.2$ \\
$6.10^{-10}$ & $3.10^{-5}$ & $51 \pm 1.5$ \\
\hline
\end{tabular}

${ }^{1}$ Mean values of triplicate analysis.

(about 10-fold less than the amount usually used to make rennet milk gel) at low temperature $\left(4^{\circ} \mathrm{C}\right)$ in order to slow the rate of $\kappa$-casein hydrolysis and to better control the enzymatic reaction inhibition. According to van Hooydonk et al. (1984), the temperature coefficient $\mathrm{Q}_{10}$ for $\kappa$-casein hydrolysis by chymosin varied between 1.3 and 2.0. On the other hand, the aggregation of para$\kappa$-casein micelles did not occur at temperatures lower than $15^{\circ} \mathrm{C}$. After incubation of milk overnight with different concentrations of chymosin, $\kappa$-casein conversion was stopped by adding to milk an appropriate amount of pepstatin A to finally obtain a degree of $\kappa$-casein hydrolysis comprised between 19 and 51\% (Table 1). Pepstatin A, which contains the unusual amino acid statine ((3S, 4S)-4-amino-3-hydroxy-6-methylheptanoic acid), is recognized to be a universal and specific inhibitor of the members of the aspartic proteinase family as chymosin (Davies, 1990). The effectiveness of the hydrolysis inhibition was verified by CMP measurements realized on milk incubated at $30^{\circ} \mathrm{C}$ during $24 \mathrm{~h}$ after pepstatin A addition. Several E/I ratios have been tested and CMP measurements indicated that a molar ratio $\mathrm{E} / \mathrm{I}$ of $2.10^{-5}$ was necessary to have a complete inhibition of the reaction.

\section{Physicochemical Properties of Partially Converted Casein Micelles}

As expected, casein micelles size, zeta potential, and micellar hydration were both affected by partial hydrolysis of milk by chymosin (Table 2). Results indicated a reduction in the net negative charge of casein micelles as related to the degree of $\kappa$-casein hydrolysis that was accompanied by a small but significant decrease in hydrodynamic diameter and micellar hydration. Zeta $(\zeta)$ potential obtained for untreated milk $(-20 \mathrm{mV})$ was in accordance with values previously reported by Dalgleish (1984). $\zeta$-Potential obtained for casein micelles hydrolyzed by chymosin at $51 \%(-13.75 \mathrm{mV})$ appeared also consistent with result obtained by Dagleish (1984) for renneted micelles $(-11 \mathrm{mV})$, indicating a good correlation between the reduction of $\zeta$-potential values (Table 2) induced by the chymosin treatment and the 
Table 2. Casein micelles hydrodynamic radius, zeta potential value, and micellar hydration as related to the degree of $\kappa$-casein conversion.

\begin{tabular}{llll}
\hline $\begin{array}{l}\text { Degree of } \kappa \text {-casein } \\
\text { conversion }(\%)\end{array}$ & $\begin{array}{l}\text { Hydrodynamic radius }{ }^{1} \\
(\mathrm{~nm})\end{array}$ & $\begin{array}{l}\text { Zeta potential value }^{1} \\
(\mathrm{mV})\end{array}$ & $\begin{array}{l}\text { Micellar hydration }^{2} \\
(\mathrm{~g} \mathrm{H} \mathrm{O} / \mathrm{g} \text { dry pellet })\end{array}$ \\
\hline 0 & $227.5^{\mathrm{a}} \pm 0.5$ & $-20.20^{\mathrm{a}} \pm 0.06$ & $2.90^{\mathrm{a}} \pm 0.03$ \\
19 & $225.2^{\mathrm{b}} \pm 0.6$ & $-17.15^{\mathrm{b}} \pm 0.08$ & $2.66^{\mathrm{b}} \pm 0.06$ \\
35 & $223.8^{\mathrm{c}} \pm 0.4$ & $-15.23^{\mathrm{c}} \pm 0.04$ & $2.51^{\mathrm{c}} \pm 0.04$ \\
51 & $222.2^{\mathrm{d}} \pm 0.3$ & $-13.75^{\mathrm{d}} \pm 0.07$ & $2.38^{\mathrm{d}} \pm 0.03$ \\
\hline
\end{tabular}

a,b,c,d Means with different superscripts differ $(P<0.05)$.

${ }^{1}$ Mean values of triplicate analysis.

${ }^{2}$ Mean values of duplicate analysis.

amount of CMP liberated. Both electrostatic and steric repulsions seemed to be high enough to prevent aggregation of casein micelles hydrolyzed by chymosin at $51 \%$.

The reduction of micellar negative charge induced by chymosin treatment was accompanied by the decrease in both hydrodynamic diameter and pellet hydration (Table 2). The gradual decrease in hydrodynamic diameter related to the increase in $\kappa$-casein hydrolysis could be attributed to the progressive cleavage of CMP by chymosin as previously shown by Walstra et al. (1981). Because casein micelle hairy layer is drained by solvent (Holt and Dalgleish, 1986), its cleavage by chymosin came with a progressive reduction in micellar hydration in accordance to Creamer (1985) and Imafidon and Farkye (1996). The total thickness of the hairy layer [between 5 and $12 \mathrm{~nm}$ according to Dalgleish (1998)] appeared slightly greater than the hydrodynamic diameter decrease $(5 \mathrm{~nm})$ observed for the higher degree of $\kappa$-casein conversion (51\%). Nevertheless, in these conditions, the amount of CMP remaining at the micellar surface seemed to be sufficient to induce both stearic and electrostatic repulsions between micelles.

\section{Rheological Properties of Acid Milk Gels Made with Partially Converted Casein Micelles Compared with Strictly Acid and Rennet Milk Gels}

Dynamic low amplitude oscillatory rheology was used to monitor the acid milk gel formation process as related to the degree of $\kappa$-casein hydrolysis. As shown in Figure 1 , the conditions of acidification were identical in the different types of gels formed. On the other hand, preliminary assays (results not shown) have permitted to assess that addition of DMSO and pepstatin A, from 1 to $3.10^{-5} M$, to milk had no effect on both gelation time and $\mathrm{pH}$ of resulting acid milk gels. Curves of the changes in $G^{\prime}$ and $G^{\prime \prime}$ as a function of time indicated a decrease of the gelation time (time at $G^{\prime}=G^{\prime \prime}$ ) with increasing the degree of $\kappa$-casein hydrolysis (Figure 2). The comparison of the $\mathrm{pH}$ values at gelation time showed an increase in the gelation $\mathrm{pH}$ as a function of the degree of $\kappa$-casein hydrolysis (Table 3 ). In accordance with the model developed by Horne (1998), the increase in the $\mathrm{pH}$ of gelation as increasing the degree of $\kappa$-casein hydrolysis could be interpreted as a shift of the forces balance in favor of the hydrophobic interactions allowing aggregation to proceed. The decrease in electrosteric repulsions due to the partial hydrolysis of $\kappa$-casein could be reinforced by the drop of $\mathrm{pH}$ that could alter the steric stabilizing capacity of the hairy layer (Horne, 1999). Previous report (van Hooydonk et al., 1986) that indicated a decrease in the percentage of $\mathrm{CMP}$ removed at the clotting time as lowering milk $\mathrm{pH}$ could also support this hypothesis.

Comparison of the storage and loss moduli of acid gels made with partially $\kappa$-casein hydrolyzed milk showed that chymosin hydrolysis before GDL addition had a marked effect on formation and aging of gels (Figure 2). As shown in Table 4, the moduli values $\left(G^{\prime}\right.$ and $\left.G^{\prime \prime}\right)$ reached 1 and $2 \mathrm{~h}$ after the gelation time increased with the level of $\kappa$-casein hydrolysis. For comparison, moduli values of a gel made at $30^{\circ} \mathrm{C}$ by rennet addition were also shown (Table 4). Values obtained with partially hydrolyzed milk were in all cases (19, 35 , and $51 \%$ hydrolysis) significantly higher than those of rennet milk gel. On the contrary, moduli values of rennet milk gel were as expected higher than those of strictly acid milk gel ( $0 \%$ hydrolysis).

The rate of change in $\mathrm{G}^{\prime}$ with time $\left(\Delta \mathrm{G}^{\prime} / \Delta \mathrm{t}\right)$ as a function of time of acid milk gels made with partially converted casein micelles were compared to those of

Table 3. Gelation time and $\mathrm{pH}$ obtained for acid milk gel made by glucono- $\delta$-lactone addition as a function of the degree of $\kappa$-casein hydrolysis.

\begin{tabular}{lll}
\hline $\begin{array}{l}\text { Degree of } \kappa \text {-casein } \\
\text { hydrolysis }(\%)\end{array}$ & $\begin{array}{l}\text { Gelation time } \\
(\mathrm{min})\end{array}$ & Gelation $\mathrm{pH}^{1}$ \\
\hline 0 & $72.2 \pm 1.3$ & $5.15 \pm 0.03$ \\
19 & $40.1 \pm 0.9$ & $5.38 \pm 0.02$ \\
35 & $26.5 \pm 0.4$ & $5.48 \pm 0.01$ \\
51 & $18.3 \pm 0.7$ & $5.65 \pm 0.02$ \\
\hline
\end{tabular}

${ }^{1}$ Mean values of duplicate analysis. 


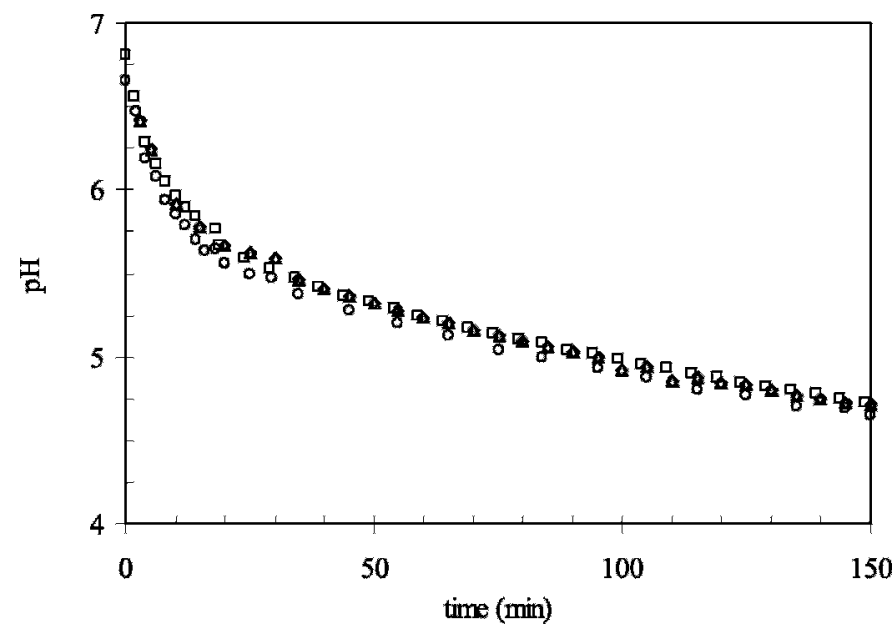

Figure 1. Effect of the degree of $\kappa$-casein hydrolysis on $\mathrm{pH}$ values as a function of time at $30^{\circ} \mathrm{C}$ after glucono- $\delta$-lactone addition $(2 \%$, wt/vol): $0 \%, \diamond ; 19 \%, \bigcirc ; 35 \%, \triangle ; 51 \%, \square$. Mean values of duplicate experiment.

strictly acid and rennet gel (Figure 3 ). The initial rate of gel firmness $\left(\Delta \mathrm{G}^{\prime} / \Delta \mathrm{t}\right)$ appeared steeper for acid gels made with chymosin hydrolyzed milk than those of strictly acid gel. On the contrary, no significant difference was observed in regard to the initial rate of gel firmness for acid gels made at the three levels of chymosin hydrolysis $(19,35$, and $51 \%)$. For these three acid gels, the rate of change in $\mathrm{G}^{\prime}$ with time appeared quite complex with two stages separated by a shoulder (shallow local minimum in the curve) which corresponded to $\mathrm{pH}$ values of $5.3,5.2$, and 5.15 for acid gel made with milk hydrolyzed at 51,35 , and $19 \%$, respectively. During this second stage, the curves of $\Delta \mathrm{G}^{\prime} / \Delta \mathrm{t}$ continued to rise as a function of time, without important changes in the shape of the curves. Although the slope of the three curves appeared identical during the first stage, a small increase in the slope of the curves could be noted during the second stage as increasing the level of $\kappa$-casein hydrolysis (Figure 3 ). The effect of the extent of $\kappa$-casein hydrolysis on gel formation appeared to be more significant in the second stage of the change in $\mathrm{G}^{\prime}$ with time than in the first one, i.e., as soon as the $\mathrm{pH}$ value of about 5.2 has been reached. The higher values of gel firmness obtained at $\operatorname{tg}+1 \mathrm{~h}$ and $\operatorname{tg}+2$ $\mathrm{h}$ for acid gels made with hydrolyzed milk (Table 4) seemed to be a consequence of the important increase in the rate of gel firming during the second stage of the time derivative $\mathrm{G}^{\prime}$ curves. Rennet milk gel exhibited steeper initial rate of gel formation than acid gels made with chymosin-treated milks but the time derivative $G^{\prime}$ curve slowed down rapidly to reach a plateau and finally decreased as previously observed for strictly acid gel (Figure 3).

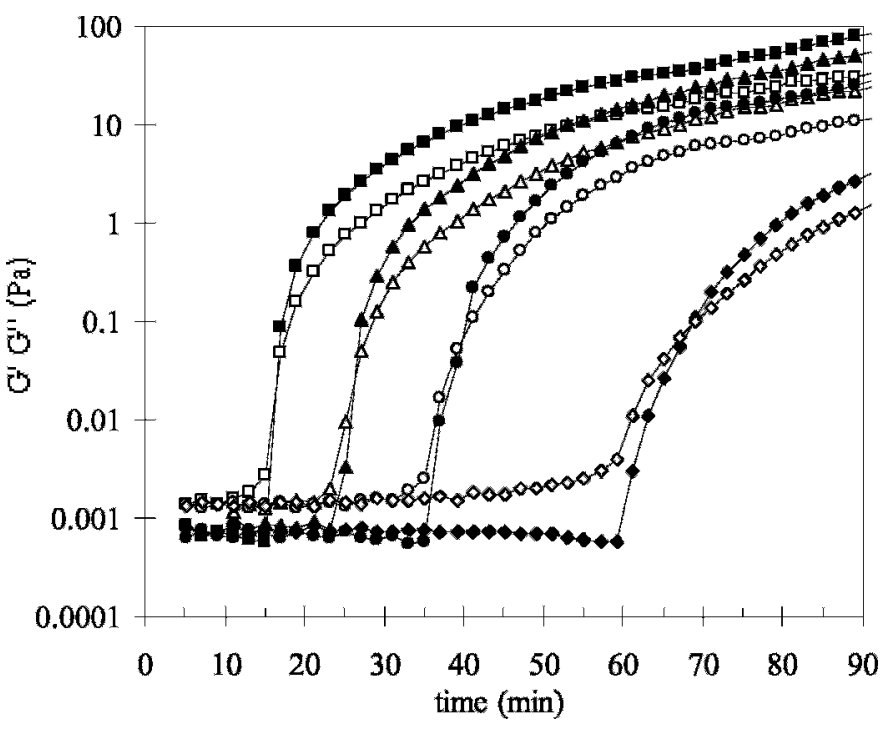

Figure 2. Effect of the degree of $\kappa$-casein hydrolysis on the storage $\left(G^{\prime}\right.$ : plain symbol) and the loss $\left(G^{\prime \prime}\right.$; open symbol) moduli of acid gel made by glucono- $\delta$-lactone addition as function of time at $30^{\circ} \mathrm{C}: 0 \%$, $\diamond \diamond ; 19 \%, \bullet \bigcirc ; 5 \%, \boldsymbol{\Delta} \triangle ; 51 \%, \square \square$. Mean values of duplicate experiment.

The particular shape of the time derivative $G^{\prime}$ curves obtained for acid gels made with partially chymosinhydrolyzed milk could be related to results recently reported by Tranchant et al. (2001). According to these authors, the curves of $\Delta \mathrm{G}^{\prime} / \Delta \mathrm{t}$ obtained for milk acidified in minimal renneting conditions presented also irregularities ("maximum-minimum") near $\mathrm{pH} 5.2$ (approximately $40 \%$ hydrolysis of $\kappa$-casein) that were more pronounced than those shown in Figure 3. However, in the present study, the $\kappa$-casein hydrolysis of milk was controlled before GDL addition contrarily to the study presented by Tranchant et al. (2001) in which milk acidification and renneting evolved simultaneously.

The changes in $\tan \delta$ values during the formation of the different types of gels studied were presented in Figure 4. A maximum in tan $\delta$ was observed at about pH 5.2 for acid gels made with chymosin-hydrolyzed milk, whatever the degree of hydrolysis, whereas a shoulder was noted around $\mathrm{pH} 5.1$ for strictly acid gel ( $0 \%$ hydrolysis). After this maximum (or shoulder in the case of acid gel) $\tan \delta$ decreased progressively, and the rate of decrease tended to fall with time. In contrast, no maximum was observed for rennet gel and $\tan \delta$ continued to decrease until reaching a plateau (Figure 4). Such behavior in $\tan \delta$ was recently reported by Lucey et al. (2000) for both GDL and combined gels made with heated milk. In all cases the maximum in $\tan \delta$ was observed around $\mathrm{pH} 5.15$. A maximum in tan $\delta$ in the same range of $\mathrm{pH}$ was also noted by Tranchant et al. (2001) for acid and combined gels. Likewise higher 
Table 4. Storage and loss moduli values ${ }^{1}$ of acid milk gel with different degree of $\kappa$-casein hydrolysis and rennet milk gel determined at 1 and $2 \mathrm{~h}$ after their gelation time (tg).

\begin{tabular}{|c|c|c|c|c|}
\hline Type of gel & $\begin{array}{l}\mathrm{G}^{\prime}(\mathrm{Pa}) \\
\text { at tg }+1 \mathrm{~h}\end{array}$ & $\begin{array}{l}\mathrm{G}^{\prime \prime}(\mathrm{Pa}) \\
\text { at } \mathrm{tg}+1 \mathrm{~h}\end{array}$ & $\begin{array}{l}\mathrm{G}^{\prime} \\
\text { at } \operatorname{tg}+2 \mathrm{~h}\end{array}$ & $\begin{array}{l}\mathrm{G}^{\prime \prime} \\
\text { at } \operatorname{tg}+2 \mathrm{~h}\end{array}$ \\
\hline \multicolumn{5}{|l|}{ Acid milk gel } \\
\hline $0 \% \kappa$-casein hydrolyzed & $19.7 \pm 1.5$ & $6.7 \pm 0.3$ & $37.8 \pm 0.5$ & $10.8 \pm 0.3$ \\
\hline $19 \% \kappa$-casein hydrolyzed & $38.4 \pm 1.4$ & $15.7 \pm 0.2$ & $116.2 \pm 0.6$ & $36.1 \pm 0.9$ \\
\hline $35 \% \kappa$-casein hydrolyzed & $47.2 \pm 1.8$ & $21.2 \pm 0.4$ & $177.2 \pm 1.1$ & $61.6 \pm 0.8$ \\
\hline $51 \% \kappa$-casein hydrolyzed & $52.7 \pm 1.7$ & $25.0 \pm 0.3$ & $192.0 \pm 1.5$ & $76.6 \pm 0.7$ \\
\hline Rennet milk gel & $40.0 \pm 1.5$ & $11.2 \pm 0.2$ & $80.0 \pm 0.9$ & $24.2 \pm 0.4$ \\
\hline
\end{tabular}

${ }^{1}$ Mean values of duplicate experiment.

values of $\tan \delta$ were found by Roefs et al. (1990b) at $\mathrm{pH}$ 5.2 for gels made by acidification with $\mathrm{HCl}$ in the cold and renneting. All of these observations permitted us to assess that the maximum in $\tan \delta$ appeared as a $\mathrm{pH}-$ induced effect only and was independent of the extent of $\kappa$-casein hydrolysis or the aging time of the gel. As reported by Lucey et al. (2000) for combined gels, the solubilization of CCP at low $\mathrm{pH}$ values led to a partial loosening of bonds within the casein particles in gel network. Solubilization of CCP may alter the balance between viscous and elastic components in the network modifying protein-protein interactions, and hence may be responsible for the increased loss tangent of gel observed.

Results obtained indicated that partial chymosin-hydrolysis of milk prior to GDL addition caused much stiffer gels to be formed. As previously reported by Roefs et al. (1990b) higher values of teh storage moduli were found for gels obtained by combining acidification at $\mathrm{pH} 5.1$ (or below) and renneting compared with those observed for strictly acid gels. In agreement with Tran-

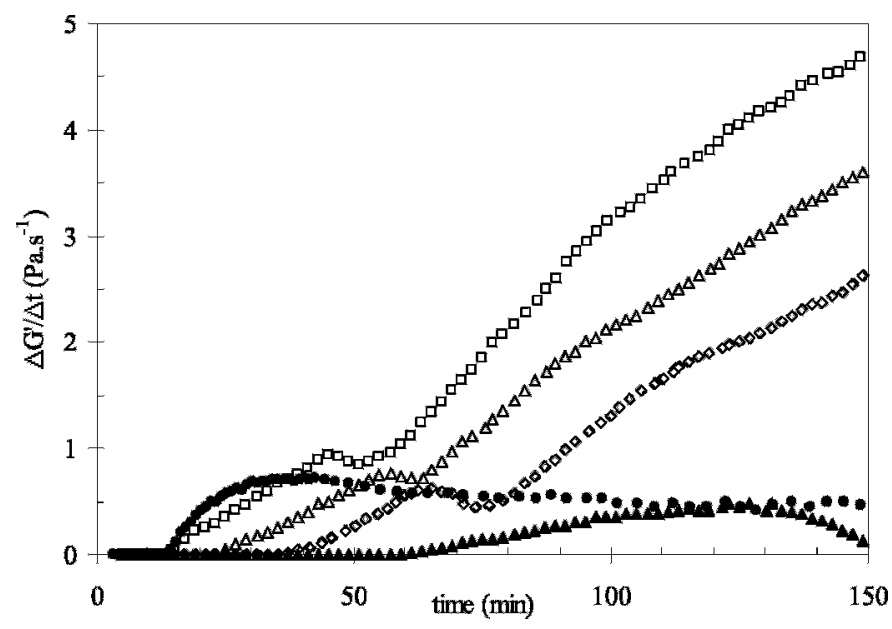

Figure 3. Changes in $\Delta \mathrm{G}^{\prime} / \Delta \mathrm{t}$ as a function of time for acid glucono$\delta$-lactone gels made with increasing degree of $\kappa$-casein hydrolysis: $0 \%, \mathbf{\Delta} ; 19 \%, \diamond ; 35 \%, \triangle ; 51 \%, \square$, and for rennet milk gel $\bullet$ (at $30^{\circ} \mathrm{C}$ ). Mean values of duplicate experiment. chant et al. (2000), the effects of partial $\kappa$-casein hydrolysis and milk acidification appeared as synergistic, with acidification enabling the aggregating tendency of partial hydrolyzed casein particles. The unmasking of supplementary reactive sites on casein mielles due to the release of CMP might counterbalance the destabilizing effect of casein demineralization on gel cohesivness and contribute to reinforce the structure of the gel. According to Roefs et al. (1990b) an important and gradual increase in $\mathrm{G}^{\prime}$ with time might be largely attributed to increased fusion of casein particles due to rearrangement of both inter- and intramolecular forces. Such behavior was observed for acid gels made with partially chymosin-hydrolyzed milk after the gel has formed and especially from $\mathrm{pH} 5.2, \mathrm{pH}$ range where an extensive fusion of casein particles coming with important protein conformational rearrangements was previously reported by Gastaldi et al. (1996).

\section{Relation Between Rheological Properties and Water-Holding Capacity of Acid Milk Gels Made with Partially Converted Casein Micelles}

Table 5 summarizes loss tangent values and serumholding capacity of gels made by GDL addition in milk

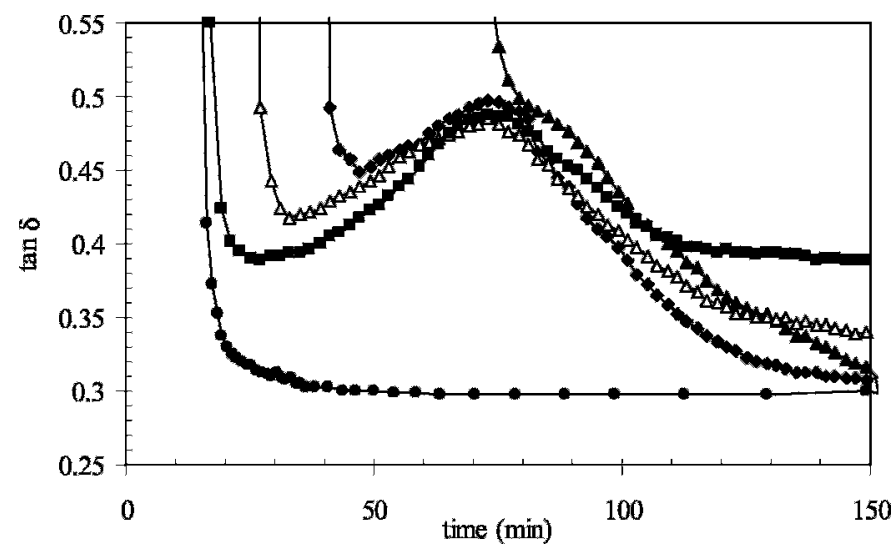

Figure 4. Changes in loss tangent $(\tan \delta)$ as a function of time for acid glucono- $\delta$-lactone gels made with increasing degree of $\kappa$ casein hydrolysis and for rennet milk gel (at $\left.30^{\circ} \mathrm{C}\right)$ : $0 \%, \boldsymbol{\Delta} ; 19 \%$, $35 \%, \triangle ; 51 \%$,, and for rennet milk gel, $\bullet$ (at $30^{\circ} \mathrm{C}$ ). Mean values of duplicate experiment. 
Table 5. Loss tangent values ( $\tan \delta$ ), serum-holding capacity [g of serum drained/100 g of gel (\%)] and $\mathrm{pH}$ of acid milk gels with different degree of $\kappa$-casein hydrolysis and rennet milk gel determined at $2 \mathrm{~h}$ after their point of gel (tg).

\begin{tabular}{llll}
\hline Type of gel & Tan $\delta^{1}$ & $\begin{array}{l}\text { Serum-holding } \\
\text { capacity }(\%)^{2}\end{array}$ & $\mathrm{pH}^{1}$ \\
\hline $\begin{array}{l}\text { Acid milk gel } \\
0 \% \kappa \text {-casein hydrolyzed }\end{array}$ & $0.28^{\mathrm{a}} \pm 0.02$ & $82.12^{\mathrm{a}} \pm 0.12$ & \\
$19 \% \kappa$-casein hydrolyzed & $0.31^{\mathrm{b}} \pm 0.01$ & $85.91^{\mathrm{b}} \pm 0.25$ & $4.67 \pm 0.02$ \\
$35 \% \kappa$-casein hydrolyzed & $0.35^{\mathrm{c}} \pm 0.03$ & $87.64^{\mathrm{c}} \pm 0.12$ & $4.76 \pm 0.03$ \\
$51 \% \kappa$-casein hydrolyzed & $0.39^{\mathrm{d}} \pm 0.02$ & $90.21^{\mathrm{d}} \pm 0.32$ & $4.90 \pm 0.04$ \\
Rennet milk gel & $0.30^{\mathrm{b}} \pm 0.01$ & $85.64^{\mathrm{b}} \pm 0.23$ & $6.67 \pm 0.03$ \\
\hline
\end{tabular}

a,b,c,d Means with different superscripts differ $(P<0.05)$.

${ }^{1}$ Mean values of duplicate experiment.

${ }^{2}$ Mean values of triplicate determination.

having different levels of $\kappa$-casein hydrolysis. A strictly rennet gel was also proposed for comparison. At a given time after gelation $(2 \mathrm{~h})$, increasing the degree of $\kappa$ casein conversion in milk led to an increase in loss tangent and serum-holding capacity of acid milk gels. As a comparison, strictly rennet gel exhibited $\tan \delta$ values and serum-holding capacity higher than strictly acid gel, but lower than acid milk gel made with chymosin treated milk at the two highest levels (35 and $51 \%$ ). The small changes in $\mathrm{pH}$ observed between different gels (Table 5) were probably insufficient to explain these results. So, acid gels made from partially converted milk appeared to be more prone to serum separation than strictly acid gels. Such behavior might be explained by taking into consideration the effects of $\kappa$ casein hydrolysis which is thought to alter mainly the type of interactions involved in gel network.

In general, most rheological parameters characterizing milk gels depend on the number and strength of bonds between the casein particles, on the structure of the latter, and the spatial distribution of the strands making up these particles (Roefs et al., 1990a). According to Lankes et al. (1998), G' values resulted from stronger proteins bonds contributing to the elastics characteristics such as electrostatic interactions and hydrogen bonds, whereas $G^{\prime \prime}$ values were due to weaker bonds such as hydrophobic and Van der Waals bonds. On the other hand, $\tan \delta$ was independent of the number of bonds but was related to the types of bonds (van Vliet and Walstra 1985). As a consequence, the increase in $\tan \delta$ of acid gels made with partially converted micelles could be attributed to change in the balance between viscous and elastic components in the network in favor of weaker interactions characterized by the viscous component. As reported by Roefs et al. (1990a), a higher value of $\tan \delta$ indicated an increased relaxation behavior of the protein-protein bonds that could be related to a transition from an "acid" to a "rennet" gel character (Lucey et al., 2000). On the other hand, a higher value of the loss tangent was often accompanied by an increased susceptibility of the gel to rearrangements and syneresis (Van Vliet et al., 1991). These trends appeared consistent with the increase in both $\tan \delta$ of the gel and its serum-holding capacity as increasing the level of $\kappa$ casein conversion in acid gels.

Results obtained in this study demonstrate that it is possible to modify rheological and serum-holding behavior of acid gels by changing micellar surface reactivity with controlled $\kappa$-casein chymosin hydrolysis. Although the use of Pepstatin A and DMSO appeared difficult to be applied in cheese making, acid gel made with partially chymosin hydrolyzed milk constituted an useful model system for studying the effect of changes in chemical interactions during acid milk gel formation. However, for industrial applications, complementary studies should be performed to find another way to inhibit chymosin, notably with an appropriate heating treatment.

\section{ACKNOWLEDGMENTS}

The financial support of the scientific council of the University of Montpellier II is gratefully acknowledged. Authors wish to thank Pr Blas Tarodo de la Fuente for helpful scientific advices at the initiation of this work.

\section{REFERENCES}

Bringe, N. A., and J. E. Kinsella. 1987. Forces involved in the enzymatic and the acidic coagulation of casein micelles. Pages 159 194 in Developments in Food Protein. B. J. F. Hudson, ed. Elsevier Applied Science, London, UK.

Creamer, L. K. 1985. Water absorption by renneted casein micelles. Milchwissenschaft 40:589-591.

Dalgleish, D. G. 1979. Proteolysis and aggregation of casein micelles treated with immobilized or soluble chymosin. J. Dairy Res. 46:653-661.

Dalgleish, D. G. 1984. Measurement of electrophoretic mobility and zeta potential from milk using laser doppler electrophoresis. J. Dairy Res. 51:425-435.

Dalgleish, D. G. 1998. Casein micelles as colloids: Surface structures and stabilities. J. Dairy Sci. 81:3013-3018. 
Daviau, C., M. H. Famelart, A. Pierre, H. Goudédranche, and J. L. Maubois. 2000. Rennet coagulation of skim milk and curd drainage: Effect of $\mathrm{pH}$ casein concentration, ionic strength and heat treatment. Lait 80:397-415.

Davies, D. 1990. The structure function of the aspartic proteinase. Annu. Ref. Biophys. Biophys. Chem. 19:189-215.

Gastaldi, E., A. Lagaude, and B. Tarodo de la Fuente. 1996. Micellar transition state in casein between $\mathrm{pH} 5.5$ and 5.0. J. Food Sci. 61:59-68.

Holt, C., and D. Dalgleish. 1986. Electrophoretic and hydrodynamic properties of bovine casein micelles interpreted in terms of particles with an outer hairy layer. J. Colloid Interface Sci. 114:513-524.

Horne, D. S. 1986. Steric stabilization and casein micelle stability. J. Colloid Interface Sci. 111:250-260.

Horne, D. S. 1998. Casein Interactions: casting light on the black boxes, the structure in dairy products. Int. Dairy J. 8:171-177.

Horne, D. S. 1999. Formation and structure of acidified milk gels. Int. Dairy J. 9:261-268.

Horne, D. S., and T. Parker. 1981. Factors affecting the ethanol stability of bovine milk. II. The origin of the $\mathrm{pH}$ transition. J. Dairy Res. 48:285-291.

Imafidon, G., and N. Y. Farkye. 1996. Solvatation of rennet curd from high-heat treated milk influenced by acid type and pH. J. Agric. Food Chem. 44:2560-2562.

Lankes, H., H. B. Ozer, and R. K. Robinson. 1998. The effects of elevated milk solids and incubation temperature on the physical properties of natural yoghurt. Milchwissenschaft 53:510-513.

Leonil, J., and D. Mollé. 1991. A method for determination of macropeptide by cation-exchange fast protein liquid chromatography and its use for following the action of chymosin in milk. J. Dairy Res. 43:321-328.

Lucey, J. A., M. Tamehana, H. Singh, and P. A. Munro. 2000. Rheological properties of milk gels formed by a combination of rennet and glucono- $\delta$-lactone. J. Dairy Res. 67:415-427.

Roefs, S. P. F. M., A. E. A. De Groot-Mostert, and T. van Vliet. 1990a. Structure of acid casein gels. 1. Formation and model of gel network. Colloids Surfaces 50:141-159.
Roefs, S. P. F. M., T. van Vliet, H. J. C. M. van den Bijgaaart, A. E. A. De Groot-Mostert and P. Walstra. 1990b. Structure of casein gels made by combined acidification and rennet action. Neth. Milk Dairy J. 44:159-188.

Tarodo de la Fuente, B., and C. Alais. 1975. Physicochemical studies on the enzymatic coagulation of milk. Chimia 29:379-383.

Tobitani, A., H. Yamamoto, T. Shioya, and S. B. Ross-Murphy. 1995. Rheological and structural studies on heat-induced gelation of concentrated skim milk. J. Dairy Res. 62:257-267.

Tranchant, C. C., D. G. Dalgleish, and A. R. Hill. 2001. Different coagulation behaviour of bacterologically acidified and renneted milk: The importance of fine-tuning acid production and rennet action. Int. Dairy J. 11:483-494.

van Hooydonk, A. C. M., C. Olieman, and H. G. Hagedoorn. 1984. Kinetics of the chymosin-catalysed proteolysis of $\kappa$-casein in milk. Neth. Milk Dairy J. 38:207-222.

van Hooydonk, A. C. M., I. J. Boerrigter, and H. G. Hagedoorn. 1986. $\mathrm{pH}$-induced physico-chemical changes of casein micelles in milk and their effect on renneting. 2. Effect of $\mathrm{pH}$ on renneting of milk. Neth. Milk Dairy J. 40:297-313.

van Vliet, T., and P. Walstra. 1985. Note on the shear modulas of rennet induced milk gels. Neth. Milk Dairy J. 35:115-118.

van Vliet, T., H. J. M. van Dijk, P. Zoon, and P. Walstra. 1991. Relation between syneresis and rheological properties of particles gels. Coll. Polymer Sci. 269:620-627.

Vidal, V., E. Gastaldi, E. Lefebvre-Cases, A. Lagaude, S. Marchesseau, B. Tarodo de la Fuente, and J. L. Cuq. 1998. Effect of succinylation on the rennet coagulation of milk. J. Dairy Sci. 81:69-75.

Vojdani, F., and J. R. Whitaker. 1994. Chemical and enzymatic modification proteins for improved functionality. Pages 261-309 in Food functionality in food systems. N. S. Hettiarachchy and G. R. Ziegler, ed. Marcel Dekker Inc., New York.

Walstra, P., V. A. Bloomfield, G. J. Wei, and R. Jenness. 1981. Effect of chymosin on the hydrodynamic diameter of casein micelles. Biochim. Biophys. Acta 669:258-259. 